\title{
MODELO PARA A ANÁLISE DE RISCO ECONÔMICO aplicado ao Planejamento de PRojetos de IRRIGAÇÃO PARA CULTURA DO CAFEEIRO
}

JORGE LUIZ MORETTI DE SOUZA

Tese apresentada à Escola Superior de Agricultura “Luiz de Queiroz", Universidade de São Paulo, para obtenção do título de Doutor em Agronomia, Área de Concentração: Irrigação e Drenagem.

\section{PIRACICABA}

Estado de São Paulo - Brasil

Março - 2001 


\title{
MODELO PARA A ANÁlISE DE RISCO ECONÔMICO APLICADO AO PLANEJAMENTO DE PROJETOS DE IRRIGAÇÃO PARA CULTURA DO CAFEEIRO
}

\author{
JORGE LUIZ MORETTI DE SOUZA \\ Engenheiro Agrícola
}

Orientador: Prof. Dr. JOSÉ ANTÔNIO FRIZZONE

Tese apresentada à Escola Superior de Agricultura

"Luiz de Queiroz", Universidade de São Paulo, para obtenção do título de Doutor em Agronomia, Área de Concentração: Irrigação e Drenagem.

PIRACICABA

Estado de São Paulo - Brasil

Março - 2001 


\title{
Dados Internacionais de Catalogação na Publicação (CIP) \\ DIVISÃO DE BIBLIOTECA E DOCUMENTAÇÃO - Campus “Luiz de Queiroz"/USP
}

\author{
Souza, J orge Luiz M oretti de \\ M odelo para a análise de risco econômico aplicado ao planejamento de projetos de irrigação \\ para cultura do cafeeiro / Jorge Luiz M oretti de Souza. - - Piracicaba, 2001. \\ $253 \mathrm{p}$. \\ Tese (doutorado) - - Escola Superior de A gricultura Luiz de Queiroz, \\ 2001 \\ Bibliografia. \\ 1. A nálise de risco 2. Café 3. Irrigação 4. Modelo matemáticoo 5. Tomada de decisão \\ I. Título
}

CDD 633.73

“Permitida a cópia total ou parcial deste documento, desde que citada a fonte - $O$ autor" 
Às minhas duas queridas meninas Helayne e Mariana, pelo amor e companheirismo, Dedico

À minha mãe Onélia, irmãos, parentes e amigos Homenageio 


\section{AGRADECIMENTOS}

- À Universidade Federal do Paraná pela liberação para cursar o doutorado.

- Ao Departamento de Engenharia Rural da Escola Superior de Agricultura "Luiz de Queiroz"/USP, pelo acolhimento e oportunidade de realização do curso de Doutorado.

- Ao Prof. Dr. José Antônio Frizzone, DER/ESALQ/USP, pela orientação, amizade e ensinamentos.

- Ao Programa Institucional de Capacitação de Docentes e Técnicos/CAPES, pela concessão da bolsa de estudos.

- Aos professores do curso de Pós-graduação em Irrigação e Drenagem pelo apoio e ensinamentos que contribuíram muito para minha formação.

- À todos os colegas do Depto. de Solos e Engenharia Agrícola e Depto. de Engenharia e Tecnologia Rurais, do Setor de Ciências Agrárias da Universidade Federal do Paraná, pela amizade, incentivo e liberação para realização deste curso.

- Aos Professores Antônio Augusto Alves Pereira, Masato Kobiyama, Paulo Cesar Sentelhas, Rubens Duarte Coelho e Tarlei Arriel Botrel, pelas correções e sugestões apresentadas para melhorar o trabalho desenvolvido.

- Aos colegas Eliezer Santurbano Gervásio, Luis Gustavo Barioni e Marco Antônio Fonseca Conceição, pela inestimável ajuda em algumas etapas do desenvolvimento desse trabalho.

- À todos os grandes colegas do curso pelo companheirismo, incentivo e cooperação.

- À bibliotecária Kátia M. Andrade de Ferraz, pelo auxílio na revisão bibliográfica.

- À todos aqueles que direta ou indiretamente colaboraram para que este trabalho pudesse ser realizado, meu especial agradecimento. 


\section{SUMÁRIO}

Página

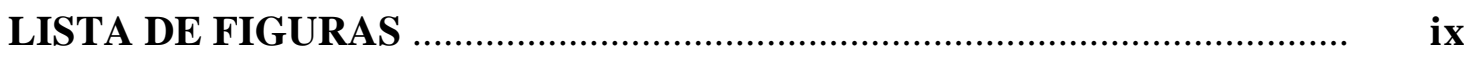

LISTA DE TABELAS …...................................................................

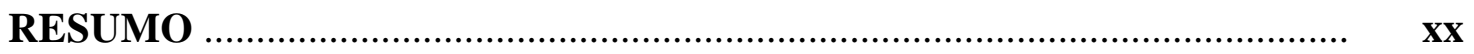

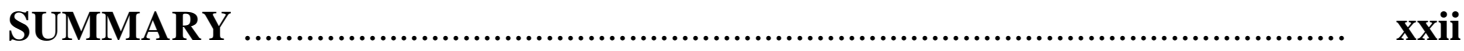



2 REVISÃO DE LITERATURA …..................................................... 4

2.1 O café - considerações gerais .......................................................................

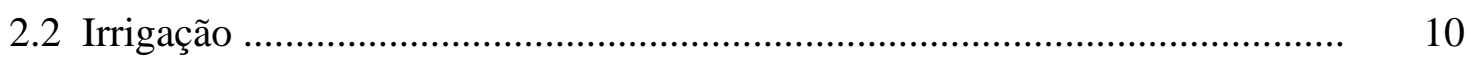

2.2.1 Considerações gerais sobre a irrigação ................................................. 10

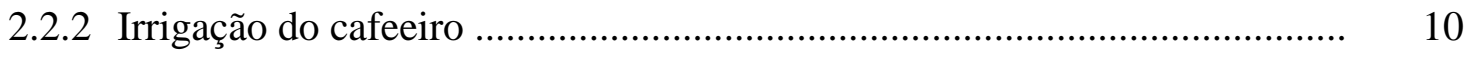

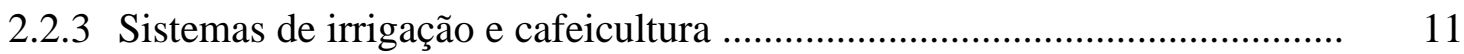

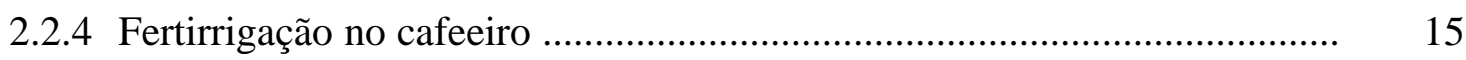

2.2.5 Deficiência hídrica nas fases de desenvolvimento do cafeeiro ................... 15

2.2.6 Parâmetros de crescimento do cafeeiro irrigado ......................................... 16

2.3 Espaçamento para o plantio do cafeeiro .................................................... 17

2.4 Produtividade do cafeeiro e sua vida útil .................................................. 19

2.5 Modelos de balanço hídrico ..................................................................... 23

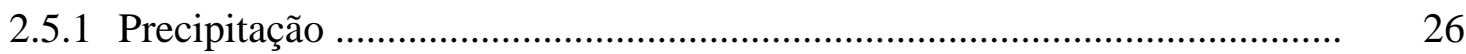

2.5.2 Evapotranspiração de referência ......................................................... 27

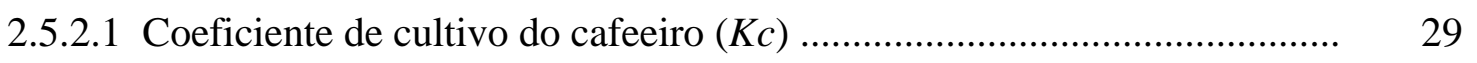

2.5.3 Armazenamento de água no solo .......................................................... 32

2.5.3.1 Profundidade do sistema radicular do cafeeiro ..................................... 33

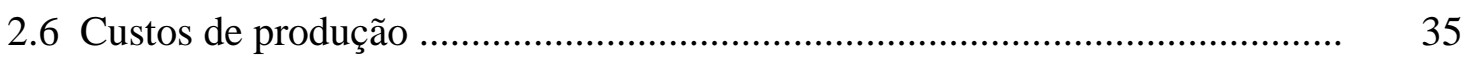

2.6.1 Custos fixos na cafeicultura e irrigação .................................................. 37

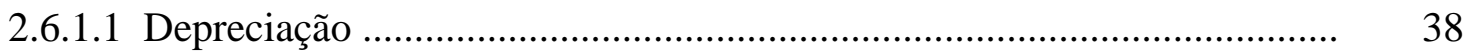

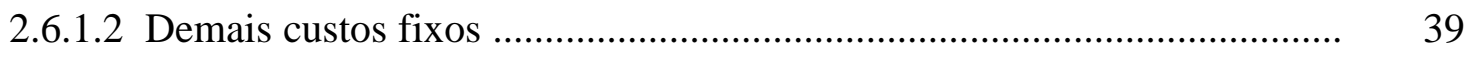

2.6.2 Custos variáveis na cafeicultura e irrigação ............................................ 39

2.6.2.1 Comentário sobre alguns componentes dos custos variáveis .................. 39

2.6.3 Custo do sistema de irrigação ............................................................... 42

2.6.4 Custo total da cafeicultura com irrigação ................................................ 43 


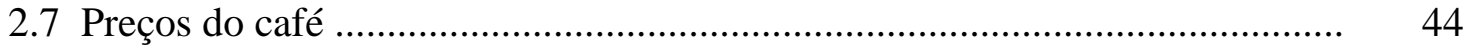

2.8 Critérios de análise econômica ....................................................................... 47

2.9 Modelos aplicados à análise de risco ............................................................ 48

3 MATERIAL E MÉTODO _.............................................................. 51

3.1 Etapas de desenvolvimento do trabalho ....................................................... 51

3.2 Modelo proposto ................................................................................ 52

3.2.1 Simulação do balanço hídrico decendial ..................................................... 52

3.2.1.1 Valores decendiais de precipitação provável ........................................... 53

3.2.1.2 Valores decendiais da evapotranspiração de referência ............................. 53

3.2.1.3 Valores dos coeficientes de cultivo ...................................................... 54

3.2.1.4 Armazenamento de água no solo ....................................................... 54

3.2.1.5 Manejo da irrigação ........................................................................ 56

3.2.2 Volume bruto de água e tempo gasto anualmente nas irrigações ................ 57

3.2.3 Cálculo do faturamento da energia elétrica ............................................. 58

3.2.3.1 Tarifa convencional ......................................................................... 60

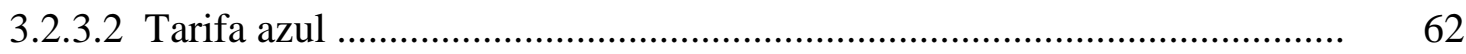

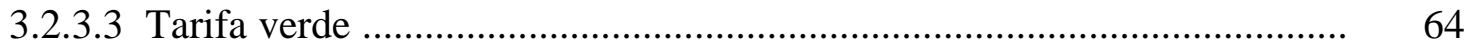

3.2.3.4 Utilização das equações de tarifas horo-sazonais no trabalho ................... 66

3.2.4 Estimativa do consumo de energia elétrica pelo sistema de irrigação ......... 67

3.2.5 Cálculo do consumo e despesas com diesel ............................................... 68

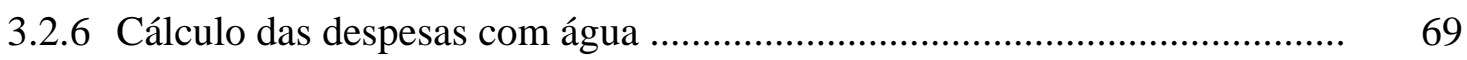

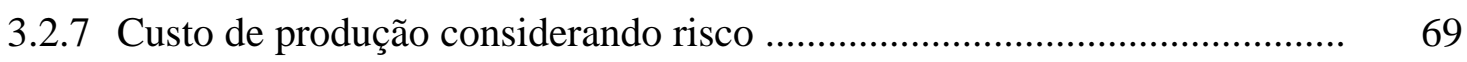

3.2.7.1 Custos variáveis .......................................................................... $\quad 70$

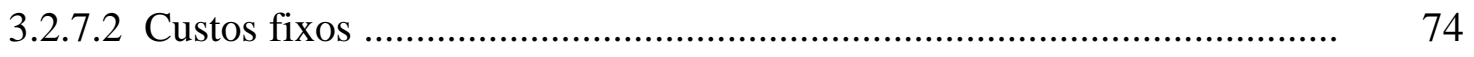

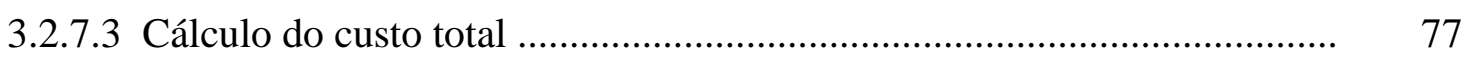

3.2.7.4 Cálculo dos benefícios ..................................................................... 77

3.2.7.5 Critérios de avaliação econômica ………………................................... 80

3.2.8 Análise estatística dos dados amostrados .................................................. 81

3.2.9 Processo de simulação ........................................................................... 83

3.2.9.1 Distribuições de probabilidade aplicadas ao método de Monte Carlo ...... $\quad 83$

3.3 Levantamento de dados para compor os "formulários ajuda" do modelo ...... 86

3.4 Dados para aplicação do modelo ……………………………………......... 86

3.4.1 Local para realização das análises ............................................................ 86

3.4.1.1 Características climáticas das regiões onde estão as propriedades ........... 87

3.4.1.2 Identificação e Especificação das duas propriedades ................................ 88

3.4.1.3 Sistema de irrigação e fonte de energia ..................................................... 88 
3.4.2 Dados meteorológicos ......................................................................... 89

3.4.2.1 Valores de evapotranspiração de referência e precipitação provável ....... 90

3.4.2.2 Evapotranspiração da cultura $(E T c)$ e coeficientes de cultivo $(K c)$.......... $\quad 92$

3.4.2.3 Armazenamento de água no solo ......................................................... 93

3.4.2.4 Manejo da irrigação ............................................................................ 94

3.4.3 Quantificação dos itens do custo fixo e variável ........................................ 94

3.4.3.1 Dados para realização do teste de aderência e determinação dos parâmetros estatísticos ......................................................................... 97

4 RESULTADOS E DISCUSSÃO ………………...................................... 98

4.1 Descrição da estrutura desenvolvida no modelo .............................................. 98

4.1.1 Fluxograma dos principais arquivos de utilização do modelo ..................... 100

4.1.2 Arquivos de utilização ...................................................................... 102

4.1.3 Identificação e especificação dos cenários .................................................. 103

4.1.4 Balanço hídrico climatológico decendial .................................................. 105

4.1.4.1 Valores decendiais de precipitação provável ........................................... 105

4.1.4.2 Simulação dos valores decendiais da evapotranspiração de referência .... 106

4.1.4.3 Valores dos coeficientes de cultivo ....................................................... 108

4.1.4.4 Manejo da irrigação ............................................................................... 109

4.1.4.5 Armazenamento de água no solo ......................................................... 110

4.1.4.6 Simulação do balanço hídrico decendial ..................................................... 111

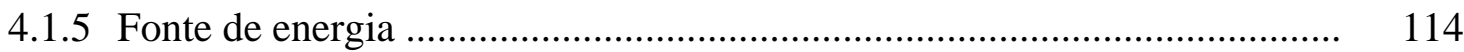

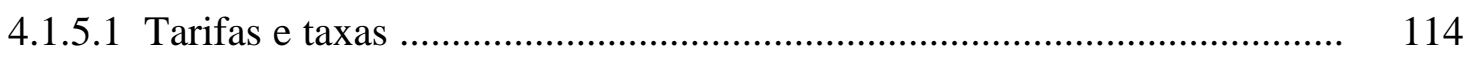

4.1.5.2 Opções para o cálculo dos gastos com energia e água ............................. 115

4.1.5.3 Simulação dos gastos com energia e água nas irrigações .......................... 117

4.1.5.4 Linhas de transmissão ...................................................................... 118

4.1.6 Parâmetros dos itens do custo de produção ……………………………...... 119

4.1.6.1 Parâmetros estatísticos dos itens que participam do custo de produção ... $\quad 120$

4.1.6.2 Tabelas auxiliares .......................................................................... 122

4.1.7 Análise estatística dos dados amostrados .............................................. 123

4.1.7.1 Frequiência e teste de aderência dos dados amostrados ........................... 123

4.1.8 Custo de produção com análise de risco ................................................... 127

4.1.8.1 Opções para análise dos itens do custo de produção .................................. 127

4.1.8.2 Resultado da análise de simulação do custo de produção ........................ 129

4.1.8.3 Freqüência encontrada nas simulações .................................................... 131

4.1.8.4 Resultados do custo de produção ao longo da vida útil da cultura ........... 132

4.1.9 Módulos e formulários informativos ..................................................... 132 
4.1.10 Considerações quanto a utilização do modelo ....................................... 135

4.2 Aplicação do modelo ................................................................................. 137

4.2.1 Avaliação do módulo "Balanço hídrico climatológico decendial" .............. 137

4.2.1.1 Considerações quanto a evapotranspiração das duas regiões .................. 137

4.2.1.2 Considerações quanto a precipitação provável nas duas regiões ............. 139

4.2.1.3 Considerações quanto ao número adequado de simulações .................... 141

4.2.1.4 Valores de evapotranspiração da cultura (ETc), observados e simulados nas duas regiões

4.2.1.5 Valores de irrigação, evapotrasnpiração real, deficiência e excedente hídrico simulados para as duas propriedades

4.2.1.6 Simulação do balanço hídrico climatológico para Fazenda Macaubas a partir da precipitação provável de Lavras

4.2.1.7 Resultados alcançados com o módulo "Balanço hídrico climatológico" . 164

4.2.2 Avaliação do módulo "Fonte de energia" ................................................ 167

4.2.2.1 Considerações quanto a composição do "cenário fonte de energia" ........ 167

4.2.2.2 Determinação do consumo e gasto anual com energia elétrica ................. 167

4.2.2.3 Determinação do consumo e gasto com diesel ....................................... 173

4.2.2.4 Determinação do consumo e gasto com água ....................................... 176

4.2.2.5 Simulação dos gastos com energia e água na Fazenda Macaubas a partir da precipitação provável de Lavras ....

179

4.2.2.6 Resultados alcançados no módulo "Fonte de energia" ............................ 181

4.2.3 Avaliação do módulo "Análise estatística dos dados amostrados” ............ 182

4.2.4 Avaliação do módulo "Custo de produção com análise de risco" .............. 184

4.2.4.1 Avaliação das séries de preços do café .................................................... 184

4.2.4.2 Percentagem ótima de venda do café ao longo dos trimestres do ano ...... 187

4.2.4.3 Função de produção do cafeeiro .............................................................. 190

4.2.5 Análise da cafeicultura irrigada sob condição de risco econômico ............. 200

4.2.5.1 Análise da cafeicultura irrigada na propriedade Faria ........................... 203

4.2.5.2 Análise da cafeicultura irrigada na propriedade Macaubas .................... 214

4.2.5.3 Consideração de eventualidades na cafeicultura irrigada ........................ 226

4.2.5.4 Considerações gerais sobre os resultados obtidos com o módulo "Custo 232 de produção com análise de risco"

5 CONCLUSÕES

6 CONSIDERAÇÕES PARA O APERFEIÇOAMENTO DO MODELO ... 236

REFERÊNCIAS BIBLIOGRÁFICAS .................................................... 239

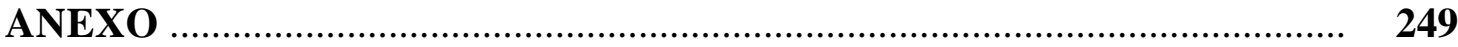




\section{LISTA DE FIGURAS}

Página

1 Zoneamento agroclimático para a cultura do café arábica no Estado de Minas Gerais, realizado por Antunes (1978) .

2 Índice sazonal do preço pago ao produtor paulista pela saca de café de $60 \mathrm{~kg}-1980$ a 1997

3 Preço do café no Brasil: ano cívil 1969 a 1997 ......................................... 46

4 Fluxo da depreciação linear, dentro de uma mesma simulação ..................... 75

5 Esquema do fluxo de caixa de um projeto ................................................. 81

6 Tela inicial do "Modelo para a análise de risco econômico aplicado ao planejamento de projetos de irrigação para cultura do cafeeiro"

7 Índice geral para acessar os "arquivos de utilização" do MORETTI .

8 Exemplo de "formulário índice" que é aberto a partir dos botões de comando existentes no "formulário índice geral" do MORETTI

9 Fluxograma da estrutura principal do MORETTI

10 Formulário para introduzir as informações sobre a propriedade, no módulo "Identificação e especificação dos cenários" do MORETTI

11 Formulário para introduzir as especificações nas caixas de opção, no módulo "Identificação e especificação dos cenários do MORETTI

12 Formulário para introduzir o valor da precipitação provável de uma região, no módulo "Balanço hídrico climatológico decendial" do MORETTI ....

13 Formulário destinado à entrada dos valores de ETo de uma região, no módulo "Balanço hídrico climatológico decendial" do MORETTI ...

14 Formulário destinado à entrada dos coeficientes de cultivo medido, no módulo "Balanço hídrico climatológico decendial" do MORETTI ....

15 Formulário destinado à entrada dos coeficientes de cultivo estimados, no módulo "Balanço hídrico climatológico decendial" do MORETTI ...............

16 Formulário para a seleção e opção do manejo de irrigação, no módulo "Balanço hídrico climatológico decendial" do MORETTI

17 Formulário destinado à entrada dos dados necessários ao cálculo da $C A D \mathrm{e}$ $A D$, no módulo "Balanço hídrico climatológico decendial" do MORETTI ...

18 Formulário destinado às opções e cálculo do balanço hídrico climatológico decendial seqüencial, no MORETTI 
19 Formulário que controla a saída dos parâmetros estatísticos do balanço hídrico climatológico decendial sequiencial, simulados no MORETTI ...........

20 Formulário para introduzir as tarifas de energia elétrica e água, taxa de ICMS e preço do óleo diesel, no módulo "Fonte de Energia" do MORETTI.

21 Formulário destinado à entrada das opções para o cálculo dos gastos com energia e água, no módulo "Fonte de energia" do MORETTI

22 Formulário destinado à realização da simulação dos gastos com energia e água nas irrigações, no módulo "Fonte de energia" do MORETTI

23 Formulário para realizar a estimativa do preço de uma rede de distribuição em baixa tensão (<75kVA), no módulo "Fonte de energia" do MORETTI ..

24 Formulário para introduzir os parâmetros estatísticos das distribuições de probabilidade, que representam os indicadores econômicos dos itens dos custos fixos e variáveis, no módulo "Parâmetros dos itens do custo de produção" do MORETTI

25 Formulário destinado ao cálculo da frequiência e teste de aderência de uma amostra de dados, no módulo "Análise estatística dos dados amostrados" do MORETTI

26 Formulário para a saída dos resultado da análise do teste de aderência, no módulo "Análise estatística dos dados amostrados" do MORETTI

27 Formulário para identificação do cenário que irá armazenar os parâmetros das distribuições de probabilidade da análise estatística, no módulo "Análise estatística dos dados amostrados" do MORETTI

28 Formulário para realizar a atualização de valores monetários, no módulo "Análise estatística dos dados amostrados" do MORETTI

29 Formulário destinado à entrada das opções para a simulação da análise de custo de produção, no módulo "Custo de produção com análise de risco" do MORETTI

30 Formulário que controla a saída dos resultados da análise de custo, no módulo "Custo de produção com análise de risco" do MORETTI

31 Formulário que controla a saída dos resultados de frequiência, encontrada nas análise de simulação, no módulo "Custo de produção com análise de risco" do MORETTI

32 Formulário destinado à saída dos resultados dos itens de custo, ao longo da vida útil da cultura, no módulo "Custo de produção com análise de risco" do MORETTI

33 Valores decendiais médios da evapotranspiração de referência (ETo, mm/decêndio) para as regiões de Lavras e Araguari, MG 
34 Valores decendiais de precipitação provável a $75 \%$ de probabilidade para as regiões de Lavras e Araguari, $\mathrm{MG}$

35 Parâmetros estatísticos da ETc do cafeeiro adulto, simulados com a distribuição de probabilidade triangular, para a região de Lavras, MG

36 Parâmetros estatísticos da ETc do cafeeiro adulto, simulados com a distribuição de probabilidade normal, para a região de Lavras, MG

37 Menor valor (a), maior valor (b), moda (c) e média (d) da evapotranspiração da cultura $(E T c)$, observada e simulada pela distribuição de probabilidade triangular e normal, nos anos de desenvolvimento do cafeeiro na região de Lavras, $\mathrm{MG}$

38 Menor valor (a), maior valor (b), moda (c) e média (d) da evapotranspiração da cultura $(E T c)$, observada e simulada pela distribuição de probabilidade triangular e normal, nos anos de desenvolvimento do cafeeiro na região de Araguari, MG

39 Valores médios de irrigação (mm/ano) no ano $X n$ (cultura adulta) do cafeeiro, a partir da função exponencial e linear-exponencial, para a propriedade Faria, situada em Lavras, MG

40 Valores médios de irrigação (mm/ano) no ano $X n$ (cultura adulta) do cafeeiro, a partir da função exponencial e linear-exponencial, para a propriedade Macaubas, situada em Araguari, MG

41 Valores médios de evapotranspiração real (ER, $\mathrm{mm} / \mathrm{ano})$ no ano $X n$ (cultura adulta) do cafeeiro, a partir da função exponencial e linearexponencial, para a propriedade Faria, situada em Lavras, MG

42 Valores médios de $E R$ ( $\mathrm{mm} / \mathrm{ano})$ no ano $X n$ (cultura adulta) do cafeeiro, com a função exponencial e linear-exponencial, para a propriedade Macaubas, situada em Araguari, MG

43 Valores médios de deficiência hídrica $(D E F, \mathrm{~mm} / \mathrm{ano})$ no ano $X n$ (cultura adulta) do cafeeiro, com as funções exponencial e linear-exponencial, para a propriedade Faria, situada em Lavras, MG

44 Valores médios de deficiência hídrica $(D E F, \mathrm{~mm} / \mathrm{ano}$ ) no ano $X n$ (cultura adulta) do cafeeiro, com as funções exponencial e linear-exponencial, para a propriedade Macaubas, situada em Araguari, MG

45 Valores médios de excedente hídrico (EXC, mm/ano) nos anos de desenvolvimento do cafeeiro, obtidos a partir das funções exponencial e linear-exponencial, para a propriedade Faria, situada em Lavras, MG

46 Valores médios de excedente hídrico (EXC, mm/ano) nos anos de desenvolvimento do cafeeiro, obtidos a partir das funções exponencial e linearexponencial, para a propriedade Macaubas, situada em Araguari, MG ........

47 Valores médios da saca de café beneficiado, simulados com a série de preços da Cooparaíso, nos 18 anos de vida da cultura 
48 Valores médios da saca de café beneficiado, simulados com a série de preços do Paraná, nos 18 anos de vida da cultura

49 Variação dos valores médios da saca de café beneficiado, simulados com a série de preços do café do Cerrado, Mogiana, Sul de Minas e Paulista, nos 18 anos de vida do cafeeiro

50 Produtividades médias do cafeeiro, em 18 anos, obtidos com a função de produção (Equação 52) e manejo 6 de irrigação, para as propriedades Faria e Macaubas, situadas nas regiões de Lavras e Araguari, MG, respectivamente

51 Produtividades médias do cafeeiro, em 18 anos, com a função de produção (Equação 52) e manejo 1 de irrigação, para as propriedades Faria e Macaubas, situadas nas regiões de Lavras e Araguari, MG, respectivamente

52 Produtividades médias nas simulações, obtidas com a Eventualidade 1, na propriedade Faria, situada em Lavras, MG

53 Produtividades médias nas simulações, obtidas com a Eventualidade 2, na propriedade Faria, situada em Lavras, MG

54 Produtividades médias nas simulações, obtidas com a Eventualidade 3, na propriedade Faria, situada em Lavras, MG

55 Produtividades médias nas simulações, obtidas com a Eventualidade 4, na propriedade Faria, situada em Lavras, MG

56 Fluxo de caixa (benefício - custo total) obtido para a Fazenda Faria (Lavras, MG), utilizando o pacote tecnológico 40sc/ha e manejos de irrigação 1 e 6

57 Fluxo de caixa (benefício - custo total) obtido para a Fazenda Faria (Lavras, MG), utilizando o pacote tecnológico 60sc/ha e manejos de irrigação 1 e 6

58 Fluxo de caixa (benefício - custo total) obtido para a Fazenda Faria (Lavras, MG), utilizando o pacote tecnológico $80 \mathrm{sc} / \mathrm{ha}$ e manejos de irrigação 1 e 6

59 Fluxo de caixa (benefício - custo total) obtido para a Fazenda Macaubas (Araguari, MG), utilizando o pacote tecnológico 40sc/ha e manejos de irrigação 1 e 6.

60 Fluxo de caixa (benefício - custo total) obtido para a Fazenda Macaubas (Araguari, MG), utilizando o pacote tecnológico 60sc/ha e manejos de irrigação 1 e 6

61 Fluxo de caixa (benefício - custo total) obtido para a Fazenda Macaubas (Araguari, MG), utilizando o pacote tecnológico 80sc/ha e manejos de irrigação 1 e 6 


\section{LISTA TABELAS}

Página

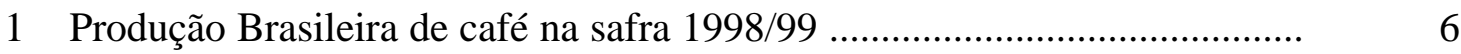

2 Cultivares e linhagens de café arábica indicadas para Minas Gerais ........... 9

3 Distribuição percentual dos cento e noventa produtores, por classe de área cultivada com café, em função do tipo de sistema de irrigação ....................

4 Dotação mensal de rega do cafeeiro, conforme o manejo, para o sistemas de irrigação pivô central, gotejamento, canhão e "tripa"

5 Turno de rega (TR), lâmina aplicada e lâmina diária, conforme o manejo e sistema de irrigação utilizado

6 Recomendação de espaçamento para o cafeeiro em dois tipos de sistema ..

7 Produtividade média de café beneficiado para algumas cultivares de café ..

8 Valores de coeficiente de cultivo do cafeeiro $(K c)$

9 Valores mensais do coeficiente de cultivo $(K c)$ do cafeeiro ........................ 31

10 Composição de custos do sistema pivô central ............................................ 42

11 Preços de mercado de alguns sistemas de irrigação na região de LavrasMG (preços em dólar comercial de 10/09/2000)

12 Temperatura média nas regiões do Triângulo Mineiro e Sul de Minas ....... 87

13 Especificação e identificação das propriedades Faria e Macaubas .............. 88

14 Dados do sistema de irrigação e fonte de energia das duas propriedades .... $\quad 89$

15 Valor mensal do coeficiente de cultivo do cafeeiro adulto ......................... 92

16 Propriedade físico-hídrica do solo ......................................................... 93

17 Fração da capacidade total de água disponível do solo .............................. 93

18 Manejos de irrigação suplementar utilizados nas análises de simulação ..... $\quad 94$

19 Pacotes tecnológicos com as especificações e quantificações dos materiais para formação e manutenção da lavoura cafeeira adensada, divulgados pela COOXUPÉ, e aplicado às propriedades Faria e Macaubas ..................

20 Pacotes tecnológicos com as especificações e quantificações dos serviços para formação e manutenção da lavoura cafeeira adensada, divulgados pela COOXUPÉ, e aplicados às propriedades Faria e Macaubas, situadas na região de Lavras e Araguari, MG, respectivamente 
21 Equações de regressão para a estimativa do custo, em dólar comercial, de uma linha de transmissão rural $(X=$ distância e $Y=$ custo da linha)

22 Parâmetros estatísticos da evapotranspiração de referência (ETo, $\mathrm{mm} /$ decêndio) nas regiões de Lavras e Araguari, $\mathrm{MG}$.....

23 Valores decendiais (mm/decêndio) de precipitação provável a 75\% de probabilidade nas regiões de Lavras e Araguari, MG

24 Parâmetros estatísticos da evapotranspiração da cultura (ETc, mm/dia) observada, nos anos de desenvolvimento do cafeeiro nas regiões de Lavras e Araguari, MG

25 Parâmetros estatísticos dos valores de evapotranspiração da cultura (ETc, mm/ano), simulados a partir da distribuição de probabilidade triangular e normal para a região de Lavras, MG

26 Parâmetros estatísticos da evapotranspiração da cultura (ETc, mm/ano), simulados a partir da distribuição de probabilidade triangular e normal para a região de Araguari, MG

27 Valores médios de irrigação (mm/ano) nos anos de desenvolvimento do cafeeiro, a partir da função exponencial (exp) e linear-exponencial (lin-exp), para a propriedade Faria, situada em Lavras, MG

28 Valores médios de irrigação ( $\mathrm{mm} / \mathrm{ano}$ ) nos anos de desenvolvimento do cafeeiro, a partir da função exponencial (exp) e linear-exponencial (lin-exp), para a propriedade Macaubas, situada em Araguari, MG .

29 Valores médios de ER (mm/ano) nos anos de desenvolvimento do cafeeiro, a partir da função exponencial (exp) e linear-exponencial (linexp), para a propriedade Faria, situada em Lavras, MG

30 Valores médios de ER (mm/ano) nos anos de desenvolvimento do cafeeiro, a partir da função exponencial (exp) e linear-exponencial (linexp), para a propriedade Macaubas, situada em Araguari, MG

31 Valores médios de deficiência hídrica ( $D E F, \mathrm{~mm} / \mathrm{ano}$ ) nos anos de desenvolvimento do cafeeiro, com a função exponencial (exp) e linearexponencial (lin-exp), na propriedade Faria, situada em Lavras, MG

32 Valores médios de deficiência hídrica ( $D E F, \mathrm{~mm} / \mathrm{ano})$ nos anos de desenvolvimento do cafeeiro, com a função exponencial (exp) e linear-exponencial (lin-exp), para a propriedade Macaubas, situada em Araguari, MG 
33 Valores médios de excedente hídrico (EXC, mm/ano) nos anos de desenvolvimento do cafeeiro, a partir da função exponencial (exp) e linear-exponencial (lin-exp), para a propriedade Faria, situada em Lavras, MG

34 Valores médios de excedente hídrico (EXC, mm/ano) nos anos de desenvolvimento do cafeeiro, a partir das função exponencial (exp) e linear-exponencial (lin-exp), para a propriedade Macaubas, situada em Araguari, MG

35 Valores anuais médios de irrigação, evapotranspiração real, deficiência e excedente hídrico, obtidos para a Fazenda Macaubas nas simulações do balanço hídrico, com a função linear-exponencial e as precipitação prováveis da região de Lavras, MG

36 Lâmina média de irrigação (mm/ano) necessária nos anos desenvolvimento da cultura do cafeeiro, nas propriedades Faria e Macaubas, situadas nas regiões de Lavras e Araguari, MG, respectivamente

37 Volume total médio de água ( $\left.\mathrm{m}^{3} / \mathrm{ano}\right)$ aplicado nas irrigações, nos anos de desenvolvimento do cafeeiro, nas propriedades Faria (13,5ha) e Macaubas (98,4ha), situadas nas regiões de Lavras e Araguari, MG, respectivamente.

38 Tempo médio (horas/ano) para realizar as irrigações ao longo dos anos de desenvolvimento da cultura do cafeeiro, nas propriedades Faria e Macaubas, situadas nas regiões de Lavras e Araguari, MG, respectivamente

39 Consumo anual médio de energia elétrica (kWh/ano), obtido nas simulações para realizar as irrigações nos anos de desenvolvimento da cultura do cafeeiro, nas propriedades Faria e Macaubas, situadas nas regiões de Lavras e Araguari, MG, respectivamente

40 Despesas anuais médias com energia elétrica, para realizar as irrigações nos anos de desenvolvimento do cafeeiro, nas propriedades Faria e Macaubas, situadas nas regiões de Lavras e Araguari, MG, respectivamente

41 Despesas anuais médias com energia elétrica (dólar/ano) na Fazenda Macaubas, situada em Araguari, MG, para realizar a irrigação do cafeeiro a partir de vários enquadramentos de tarifação horo-sazonais

42 Consumo anual médio de diesel $\left(\mathrm{m}^{3} / \mathrm{ano}\right)$ para realizar as irrigações, nos anos de desenvolvimento da cultura do cafeeiro, nas propriedades Faria e Macaubas, situadas nas regiões de Lavras e Araguari, MG, respectivamente 
43 Despesas anuais médias com diesel (dólar/ano) para realizar as irrigações, nos anos de desenvolvimento da cultura do cafeeiro, nas propriedades Faria e Macaubas, situadas nas regiões de Lavras e Araguari, MG, respectivamente

44 Despesas anuais relativas com energia elétrica e diesel, para realizar a irrigação do cafeeiro adulto, na Fazenda Macaubas, situada em Araguari, MG, a partir de vários enquadramentos de tarifação horo-sazonais

45 Despesas anuais relativas com energia elétrica e diesel, para realizar a irrigação do cafeeiro adulto (ano $X n$ ), na Fazenda Faria, situada em Lavras, MG

46 Despesas anuas médias com água (dólar/ano) para realizar as irrigações, nos anos de desenvolvimento do cafeeiro, nas propriedades Faria e Macaubas, situadas nas regiões de Lavras e Araguari, MG, respectivamente

47 Despesas anuais médias com água (dólar/ano) para realizar as irrigações, nos anos de desenvolvimento da cultura do cafeeiro, aplicando as tarifas do Projeto Senador Nilo Coelho, nas propriedades Faria e Macaubas, situadas nas regiões de Lavras e Araguari, MG, respectivamente

48 Valores anuais médios de lâmina, volume, tempo, consumo e despesas com energia e água, obtidos nas simulações para a Fazenda Macaubas, situada na região de Araguari, MG, com as precipitações prováveis da região de Lavras, MG

49 Quantificação dos serviços para manutenção e operação dos sistemas de irrigação das Fazendas Faria e Macaubas (dia-homem por ha, no ano), situadas nas regiões de Lavras e Araguari, MG, respectivamente

50 Valores médios da saca de $60 \mathrm{~kg}$ de café beneficiado, simulados a partir de cinco séries de preço, nos 18 anos de vida da cultura do cafeeiro

51 Parâmetros estatísticos médios obtidos para o preço de venda do café beneficiado, em 18 anos, e em diferentes percentagens ao longo do ano ....

52 Parâmetros estatísticos da produtividade do cafeeiro, em 18 anos, obtidos com a função de produção (Equação 52) e manejo 6 de irrigação, para as propriedades Faria $\left(\mathrm{F}^{*}\right)$ e Macaubas $\left(\mathrm{M}^{* *}\right)$, situadas nas regiões de Lavras e Araguari, MG, respectivamente

53 Parâmetros estatísticos da produtividade do cafeeiro, em 18 anos, obtidos com a função de produção (Equação 52) e manejo 1 de irrigação, para as propriedade Faria $\left(\mathrm{F}^{*}\right)$ e Macaubas $\left(\mathrm{M}^{*}\right)$, situadas nas regiões de Lavras e Araguari, MG, respectivamente 
54 Produtividades médias nas simulações, obtidas com a função de produção (Equação 52) e manejo 1 de irrigação, em conformidade com as eventualidades 1 a 4, para a propriedade Faria, situada em Lavras, MG .....

55 Opções utilizadas no módulo "Custo de produção com análise de risco", para realizar as análises de custo da cafeicultura irrigada nas Fazendas Faria e Macaubas, situadas em Lavras e Araguari, MG, respectivamente ...

56 Valor médio do custo de produção da propriedade Faria (Lavras, MG), com o pacote tecnológico de 40sc/ha e manejos de irrigação 1 a 6

57 Produtividade média (Prod.) e preço médio da saca de café beneficiado da propriedade Faria (Lavras, MG), nos anos de vida do cafeeiro, com os manejos de irrigação 1 a 6 e pacote tecnológico de 40sc/ha

58 Valor médio do custo de produção da propriedade Faria (Lavras, MG), com o pacote tecnológico de 60sc/ha e manejos de irrigação 1 a 6

59 Produtividade média (Prod.) e preço médio da saca de café beneficiado da propriedade Faria (Lavras, MG), nos anos de vida do cafeeiro, com os manejos de irrigação 1 a 6 e pacote tecnológico de 60sc/ha

60 Valor médio do custo de produção da propriedade Faria (Lavras, MG), com o pacote tecnológico de 80sc/ha e manejos de irrigação 1 a 6

61 Produtividade média (Prod.) e preço médio da saca de café beneficiado da propriedade Faria (Lavras, MG), nos anos de vida do cafeeiro, com os manejos de irrigação 1 a 6 e pacote tecnológico de 80sc/ha

62 Parâmetros estatísticos dos valores presentes líquidos, obtidos para o projeto de irrigação do cafeeiro na Fazenda Faria (Lavras, MG), considerando os pacotes tecnológicos de 40, 60 e 80sc/ha e os manejos de irrigação 1 a 6 .

63 Valor médio da taxa interna de retorno (TIR), obtida para o projeto de irrigação do cafeeiro na Fazenda Faria (Lavras, MG), considerando os pacotes tecnológicos 40, 60 e 80sc/ha e os manejos de irrigação 1 a 6 ...

64 Custos médios com o sistema de irrigação por gotejamento na propriedade Faria (Lavras, MG), adotando-se os manejos de irrigação 1 a 5 e pacotes tecnológicos de 40, 60 e $80 \mathrm{sc} / \mathrm{ha}$

65 Valores de VPL médio e TIR média, obtidos para a Fazenda Faria (Lavras, MG) com os pacotes tecnológicos de 40, 60 e 80sc/ha e manejos de irrigação 1 a 6 , desconsiderando o custo alternativo do capital de giro e fixo 
66 Valor presente líquido médio (VPL) e taxa interna de retorno média (TIR), obtidos para a Fazenda Faria (Lavras, MG) com os pacotes tecnológicos de 40, 60 e 80sc/ha e manejos de irrigação 1 a 6, considerando os custos operacionais

67 Valor médio do custo de produção da propriedade Macaubas (Araguari, MG), com o pacote tecnológico de 40sc/ha e manejos de irrigação 1 a 6 ...

68 Produtividade média (Prod.) e preço médio da saca de café beneficiado da propriedade Macaubas (Araguari, MG), nos anos de vida do cafeeiro, com os manejos de irrigação 1 a 6 e pacote tecnológico de 40sc/ha ....

69 Valor médio do custo de produção da propriedade Macaubas (Araguari, MG), com o pacote tecnológico de 60sc/ha e manejos de irrigação 1a 6 ....

70 Produtividade média (Prod.) e preço médio da saca de café beneficiado da propriedade Macaubas (Araguari, MG), nos anos de vida do cafeeiro, com os manejos de irrigação 1 a 6 e pacote tecnológico de $60 \mathrm{sc} / \mathrm{ha}$

71 Valor médio do custo de produção da propriedade Macaubas (Araguari, MG), com o pacote tecnológico de 80sc/ha e manejos de irrigação 1a 6 ....

72 Produtividade média (Prod.) e preço médio da saca de café beneficiado da propriedade Macaubas (Araguari, MG), nos anos de vida do cafeeiro, com os manejos de irrigação 1 a 6 e pacote tecnológico de $80 \mathrm{sc} / \mathrm{ha}$

73 Parâmetros estatísticos dos valores presentes líquidos (VPL), obtidos para o projeto de irrigação do cafeeiro na Fazenda Macaubas (Araguari, MG), considerando os pacotes tecnológicos 40, 60 e 80sc/ha e os manejos de irrigação 1 a 6

74 Valor médio da taxa interna de retorno (TIR), obtida para o projeto de irrigação do cafeeiro na Fazenda Macaubas (Araguari, MG), considerando os pacotes tecnológicos 40, 60 e 80sc/ha e os manejos de irrigação 1 a 6

75 Custo médio com o sistema de irrigação na propriedade Macaubas (Araguari, MG), adotando-se os manejos de irrigação 1 a 5 e pacotes tecnológicos de 40, 60 e $80 \mathrm{sc} / \mathrm{ha}$

76 Valores de VPL médio e TIR média, obtidos para a Fazenda Macaubas (Araguari, MG) com os pacotes tecnológicos de 40, 60 e 80sc/ha e manejos de irrigação 1 a 6 , desconsiderando o custo alternativo do capital de giro e fixo

77 Valor presente líquido médio (VPL) e taxa interna de retorno média (TIR), obtidos para a Fazenda Macaubas (Araguari, MG) com os pacotes tecnológicos de 40, 60 e 80sc/ha e manejos de irrigação 1 a 6 , considerando os custos operacionais 
78 Valor médio do custo de produção da propriedade Faria (Lavras, MG), com o pacote tecnológico de 60sc/ha e manejo 1 de irrigação, de acordo com as eventualidades 1 a 5

79 Produtividade média (Prod.) e preço médio da saca de café beneficiado da propriedade Faria (Lavras, MG), nos anos de vida do cafeeiro, com o pacote tecnológico de $60 \mathrm{sc} / \mathrm{ha}$, manejo 1 de irrigação e eventualidades 1 a 5

80 Parâmetros estatísticos dos valores presentes líquidos (VPL) do projeto de irrigação do cafeeiro na Fazenda Faria (Lavras, MG), considerando o pacote tecnológicos $60 \mathrm{sc} / \mathrm{ha}$, manejo 1 de irrigação e eventualidades 1 a 5 .

81 Parâmetros estatísticos das taxas internas de retorno (TIR), do projeto de irrigação do cafeeiro na Fazenda Faria (Lavras, MG), considerando o pacote tecnológico de 60sc/ha, manejo 1 de irrigação e eventualidades 1 a 5

82 Valor médio do custo de produção da propriedade Macaubas (Araguari, MG), com o pacote tecnológico de $60 \mathrm{sc} / \mathrm{ha}$ e manejo 1 de irrigação, de acordo com as eventualidades 1 a 5

83 Produtividade média (Prod.) e preço médio da saca de café beneficiado da propriedade Macaubas (Araguari, MG), nos anos de vida do cafeeiro, com o pacote tecnológico de 60sc/ha, manejo 1 de irrigação e eventualidades 1 a 5

84 Parâmetros estatísticos dos valores presentes líquidos (VPL) do projeto de irrigação do cafeeiro na Fazenda Macaubas (Araguari, MG), considerando o pacote tecnológicos 60sc/ha, manejo 1 de irrigação e eventualidades 1 a 5

85 Parâmetros estatísticos das taxas internas de retorno (TIR), do projeto de irrigação do cafeeiro na Fazenda Macaubas (Araguari, MG), considerando o pacote tecnológico de 60sc/ha, manejo 1 de irrigação e eventualidades 1 a 5

86 Parâmetros para representar os indicadores econômicos da estrutura física existente na Fazenda Faria, situada na região de Lavras, MG

87 Parâmetros para representar os indicadores econômicos da estrutura física existente na Fazenda Macaubas, situada na região de Araguari, MG

88 Parâmetros das distribuições de probabilidade triangular, normal e uniforme, que melhor se ajustaram para simular o valor/unidade dos materiais e serviços 


\title{
MODELO PARA A ANÁlISE DE RISCO ECONÔMICO APLICADO AO PLANEJAMENTO DE PROJETOS DE IRRIGAÇÃO PARA CULTURA DO CAFEEIRO
}

\author{
Autor: JORGE LUIZ MORETTI DE SOUZA \\ Orientador: Prof. Dr. JOSÉ ANTÔNIO FRIZZONE
}

\section{RESUMO}

O presente trabalho consistiu no desenvolvimento e avaliação de um modelo de simulação voltado à análise de risco econômico, servindo de auxílio nas tomadas de decisão quanto ao planejamento e gerenciamento dos projetos de irrigação da cultura do cafeeiro. A linguagem de programação utilizada foi o Visual Basic aplicada ao Excel (Linguagem de Macro), e o processo de simulação baseou-se no método de "Monte Carlo". Cuidados foram tomados para que a estrutura do modelo fosse versátil e servisse também para a solução de problemas freqüentes na agricultura irrigada.

As análises de aplicação do modelo foram feitas com os dados levantados em duas propriedades que irrigam o cafeeiro: Faria e Macaubas. A propriedade Faria situa-se na cidade de Lavras-MG, região Sul de Minas, e possui sistema de irrigação por gotejamento de 13,5ha. A propriedade Macaubas situa-se na cidade de Araguari-MG, região do Triângulo Mineiro, e possui sistema de irrigação pivô central de 98,4ha. Três pacotes tecnológicos (40, 60 e 80sc/ha), seis manejos anuais de irrigação e a ocorrência de eventualidades na vida útil da cultura, foram analisados.

O modelo desenvolvido mostrou-se eficiente para realizar os cálculos voltados ao planejamento e determinação do risco econômico da cafeicultura irrigada e a estrutura modular proposta possibilita o acompanhamento de grande parte do processo de cálculo das análises de simulação. O equacionamento proposto para estimar a 
evapotranspiração de referência (ETo), o armazenamento de água no solo, as despesas com água e energia, os benefícios e a produção, apresentaram resultados satisfatórios. As opções disponíveis, bem como os mecanismos de ajustes existentes, possibilitam a escolha das melhores alternativas e a composição de cenários para serem analisados. Com algumas modificações nas séries de preços e na função de produção, o modelo poderá ser adaptado futuramente para analisar economicamente outras culturas perenes de comportamento semelhante ao cafeeiro.

De maneira geral, as análises de risco econômico da cafeicultura irrigada, realizadas para as propriedades Faria e Macaubas, mostraram que:

- Não é viável economicamente produzir café no pacote tecnológico de 40sc/ha na propriedade Faria. Na propriedade Macaubas, o mesmo pacote tecnológico mostrou-se viável economicamente somente no manejo de irrigação suplementar durante todo o ano. Os demais manejos analisados apresentam risco de um valor presente líquido negativo.

- Os pacotes tecnológicos de 60sc/ha e 80sc/ha mostraram-se economicamente viáveis para as duas propriedades, adotando-se ou não a irrigação. O manejo de irrigação suplementar durante todo ano sempre mostrou-se a melhor alternativa econômica.

- A ocorrência de eventualidades não comprometeu a viabilidade dos dois projetos de irrigação, quando conduzidos no pacote tecnológico de $60 \mathrm{sc} /$ ha e manejo de irrigação suplementar durante todo o ano; apenas reduziram a lucratividade. A eventualidade, considerando o atraso de dois anos no início da produção da lavoura cafeeira, foi a mais prejudicial dentre aquelas analisadas.

- Em relação ao custo total de produção da cafeicultura irrigada nas duas propriedades, verificou-se nos anos de vida útil da cultura que: os serviços e os materiais foram os itens mais significativos no custo total, ficando entre 40,7\% e 60,4\% para os serviços, e entre $15,3 \%$ e $34,3 \%$ para os materiais; as despesas com energia elétrica e água são pequenas, considerando-se a irrigação suplementar durante todo o ano, as despesas nunca foram maiores que 3,8\% para a Fazenda Faria, e 5,0\% para a Fazenda Macaubas; os custos médios com o sistema de irrigação ficaram entre 10,3\% e 29,7\% para a Fazenda Faria, e entre 7,0\% e 19,4\% para a Fazenda Macaubas. 


\title{
ECONOMIC RISK ANALYSIS MODEL FOR COFFEE IRRIGATION PROJECT DESIGN
}

\author{
Author: JORGE LUIZ MORETTI DE SOUZA \\ Adviser: Prof. Dr. JOSÉ ANTÔNIO FRIZZONE
}

\section{SUMMARY}

This study shows the application of an economic risk model to help the decision makers on planning process for coffee irrigation projects. The model was built in Excel sheet using Visual Basic Macro and the simulation process used Monte Carlo method.

It was used data from two irrigated coffee farms located at Lavras, MG (13.5ha) and Araguari, MG (98.4ha). Three different yield technology levels (2,500 , $3,600,4,800 \mathrm{~kg} / \mathrm{ha})$, and six irrigation treatments were analyzed.

The model showed good efficiency in planning and economic risk determination. The methods used by the model to determine reference evapotranspiration (ETo), soil water balance, energy and water cost showed good results and enabled to determine the best economic option.

An application of the model permits the following conclusions:

- It was not economically viable to produce coffee using the $2,400 \mathrm{~kg} / \mathrm{ha}$ yield technology level at Lavras farm. The same technology level was viable when the coffee was irrigated all the year for Araguari farm;

- The 3,600kg/ha and 4,800kg/ha were economic viable for both farms and they were independent on irrigation; 
- Different sceneries were analyzed and the worst scenerie was the yield loss for two following years. Even in the worst scenerie, the $3,600 \mathrm{~kg} / \mathrm{ha}$ yield technology level showed economical viability with irrigation along all the year;

- Variable cost was the most significant cost in the coffee production. The energy and water cost represented $3.8 \%$ for Lavras farm and $5.0 \%$ for Araguari farm. The irrigation cost was in a range $10.3 \%$ to $29.7 \%$ for Lavras farm and $7.0 \%$ to $19.4 \%$ for Araguari farm. 
